\title{
A Discussion about How to Build Effective English Teaching Evaluation System, Using Enterprise Performance Measurement
}

\author{
Fang Zhang ${ }^{1}$ \\ ${ }^{1}$ Eastern Liaoning University, China \\ Correspondence: Fang Zhang, Master Degree, Associate Professor, Major in second language English teaching. \\ 304-2-8\# Taoyuanyijing Tiekuang Road, Zhenxing district, Dandong, Liaoning Province, China
}

Received: September 15, $2013 \quad$ Accepted: February 7, $2014 \quad$ Online Published: April 14, 2014

doi:10.5430/sass.v1n2p27 URL: http://dx.doi.org/10.5430/sass.v1n2p27

[Scientific Research Project] Key project in the special reform for foreign language teaching in "the 12th Five Year Plan" of Higher education institute of Liaoning province, Project Number: WYZD13032

\begin{abstract}
Since there is an agent-principal relationship between universities and teachers in the universities, the management team of universities needs to build a teaching quality measuring system to monitor and stimulate teachers' devotion to education. For English teaching, building an effective system to evaluate teaching quality of English teachers in universities plays an important role in ensuring the quality of education. This essay takes the principles and experience of enterprise performance management into account to discuss how to build an effective system of evaluating universities’ English teaching quality.
\end{abstract}

Keyvords: University English, Teaching Quality Evaluation, Balanced Score Card, Agency Theory, Goal Congruence

\section{Introduction}

Though, at present, teaching quality diagnostic and measurement system is widely adopted in university teaching, the system is unlikely to be able to fully capture the actual teaching quality as well as the teachers' teaching achievement. This is because universities lack a mechanism to help to design the teaching quality measurement and diagnostic system. Such a system in regard of teaching quality measurement is so important due to the absence of goal congruence among universities, teachers and students (Telford \& Masson, 2005). This sort of goal deviation can be explained based on Jensen and Meckling's agency theory (Jensen \& Meckling, 1976). Agency theory states that agent, during the process of working, are likely to pursuit their own interest, leading to the damage of principal's interest (Jensen and Meckling, 1976). In the context of universities, such a principal-agent relationship does exist. The universities act as employers (principal), students as customers, and teachers play the role of an agent between universities and students. In the process of teaching, teachers are likely to shirk to maximize their own personal interests (for example, to increase their benefit by reducing the cost of time and energy). Consequently, teachers tend to ignore what universities pursue such as the social responsibility of developing the young's skills, enhance the reputation of the universities and improving teaching quality. The goal incongruence between the teachers and the universities, to a large extent, deteriorates the teaching effectiveness and efficiency in universities.

To reduce or even eliminate the goal deviation, teaching quality management team should focus on each specific evaluation measure. This essay will then illustrate a way adopted by enterprises that measures teaching quality in university English teaching.

\section{The Experience from Enterprise Performance Management}

How to select appropriate measurements to evaluate employees' performance is an essential aspect in enterprise performance management. That provides valuable guidance to university English teaching quality management team in regard of choosing proper measurements to evaluate English teachers' performance. 
Since the 1990s, balanced score card, a management tool for transferring enterprises' strategies to specific evaluation measures, has been widely used among enterprises (Cobbold and Lawrie, 2002). Balanced score card divides the process of transferring strategies to evaluation measures into four perspectives, which are Financial Perspective, Consumer Perspective, Innovation and Learning Perspective and Internal Business Perspective (Kaplan and Norton, 1992). Management teams list specific goals accordingly based on the above four perspectives and then find relevant measures to motivate and guide employees to fulfill the listed favorable goals.

For example, from the Financial Perspective, since sales companies usually aim at maximizing the revenue that the employees earned, the increase rate in revenue for each sales can be used as the measure to motivate employees to fulfill the target.

From the Customer Perspective, improving customers' loyalty and increasing new customer numbers tend to be the goals of each sales department. Therefore, management team uses customers' satisfaction rate and market share to measure sales people's performance (Simons, 2000).

From the Innovation and Learning Perspective, improving employees' skills in new technology is vital for sustainable development of the company. The result of the test on the skill that employees mastered can be used as the measure to urge employees to pay proper attention to the training program provided.

The Internal Business Perspective is divided into three processes, which are Innovation Processes, Operations Processes and Post-sale service Processes (Simons, 2000). In the Innovation Processes, because enterprises generally want to survive from the fierce competition, management team can set a pre-determined percentage of new products' sold among the total products sold as the benchmark and then compare it with the actual percentage to measure employees' performance in the innovation field. In the Operations Processes, as ensuring the quality of products is a common goal among companies particularly the production department, the mal-functioned rate can be used as the measure. A certain level of mal-functioned rate can be determined in advance based on historical record. A company compares it with the actual rate to evaluate the result of production department. In the Post-sale Processes, since providing proper warranty service to customers is essential especially for retail companies and should be an important goal, customers' satisfaction in regard of post-sale services received can be the measure to help employees to remember the importance of providing appropriate post-sale services.

\section{Applying Balanced Score Card to Teaching Quality Control in University English Teaching}

Enterprise's balanced score card can be applied to quality management of university English teaching after appropriate adjustments. This section will illustrate how to make adjustments in regard of the four perspectives to make it proper for managing English teaching quality evaluation.

The Customer Perspective is relatively easier to adjust among the four perspectives. This is because students are actually a special type of customers (Crawford, 1991). According to this thought, in university English teaching, Customer Perspective can be treated as Student Perspective.

Internal Business Perspective and Innovation and Learning Perspective are also not very difficult to transfer to English teaching quality control. Since enterprises' Internal Business Perspective includes the core activities of business operation such as producing, operating and selling, that means in the field of English teaching, this perspective should include preparing teaching materials, lecturing, giving test and examination and providing post-test or post-exam feedbacks to students. This perspective can be called as Teaching Process Perspective. The Innovation and Learning Perspective can be regarded as Research and Improvement Perspective, which includes factors such as English Teachers' research, self-improvement and further study.

It is relatively difficult to adjust the Financial Perspective. The nature of English education, to a large extent, is different from business operation, the nature of which is to maximize the profit in monetary terms. However, as Simons (2000) said, financial information reflects the result of the operation of a company in a certain period of time in numerical terms. For English teaching, the quantitative teaching result should be the fourth perspective in measuring English teaching quality. The quantitative teaching result may include the mean and median of exam results, the result of continuous assessment, the employment rate of graduates, etc. This kind of assessment items can be attributed to the teaching result data level.

To sum up, English teaching quality evaluation can also be analyzed from four perspectives based on the idea of Balanced Score Card. The four perspectives are Student Perspective, Teaching Process Perspective, Research and Improvement Perspective and Quantitative Teaching Result Perspective. 


\section{Selecting University English Teaching Quality Measures Based on Balanced Score Card}

\subsection{Student Perspective}

For Student Perspective, goals should be set based on the demand of student in regard of their expectation on English learning. Currently, students' expectation on higher education's English learning can be summarized into three aspects, which are the level of professional English education they received, whether proper assistance is provided to them during English study and whether the content of learning is strongly related to employment (Davies, 2002; Tricker, 2005).

Therefore, universities and English teachers should try their best to reach students' three expectations on English learning. That means students' three expectations should be the goals of ensuring the quality of English teaching from Student's Perspective.

\subsubsection{The Level of Professional English Education Students Received}

The level of professional English education includes teachers' professional attitude and teachers' competence of English teaching. These two aspects can be used to evaluate university English teachers' performance.

As Theall (2002) says students are considered to be the only group of people who may properly comment on teachers' devotion, behavior and clearance in teaching. Students' rating on teachers' professional attitude helps to motivate teachers to pay more attention to students' feeling.

Students' rating on teachers' overall competence in teaching gives insights on teachers' professional ability. For example, whether a teacher has good pronunciation and good sense in controlling the language, theses aspects are quite difficult for the teaching quality management team to know directly while a number of teachers currently have problems in pronunciation and controlling English due to lacking the knowledge in phonology and phonetics (Zhang, 2009). The measurements in these aspects are likely to encourage university English teachers to continuously improve their English by themselves

\subsubsection{Proper Assistance Provided}

Generally, the proper assistance provided by teachers can include the satisfaction level of answering questions after class and students' self-judgment of their improvement in their self-learning capability during the process of learning English.

To be more specific, answering students' questions after class provides an effective feedback to effectiveness and quality of university English teaching (Wang, 2006). Taking this process into account helps teachers to realize the importance of providing proper answers to the confused students. Hence, English teachers are likely to be more patient when providing assistance to students.

For students' self-judgment of to improve their ability of self-learning, since answering students' questions itself is also a process of fostering students' self-learning skills, university English teachers should pay attention to motivate students to think logically and attentively when giving answers. Adding this measure to improve students' self-learning skills is also an important task during English teaching.

4.1.3 The Level of Correlation between Employment and English Teaching

According to research, currently employers pay more attention to candidates' English speaking and writing skills when selecting employees (Powers, 2010). Therefore, whether English teachers have paid appropriate attention to students' writing and speaking skills should be included as the measurement.

The measures of Student Perspective is completed by students and then collected by the management department in the universities. However, the other three perspectives are completed and collected only by the management team.

\subsection{Teaching Process Perspective}

Based on how enterprises divide the process of operating a business, universities' Teaching Process Perspective comprises three aspects, which are Pre-class Preparation, Performance in Class and Post-class Feedbacks and Assessment.

\subsubsection{Pre-class Preparation}

Universities should aim at ensuring that English teachers have fully prepared before class. The teaching quality management team can check teaching materials' preparation and teaching slides regularly and randomly, and rate on teachers' preparation based on the above checks. This not only helps to supervise English teachers' teaching preparation but also can find out the weaknesses in teachers' preparation so that corrections can be made to improve 
teaching quality.

\subsubsection{Performance in the Class}

Since the evaluation result from Student Perspective, to a large extent, can reflect the problems in teachers' performance in the class, universities' teaching management team should set ensuring teaching task's fulfillment as the goal during the process of evaluation. Measures such as whether teachers are late or even absent for the class and whether the teaching process is smooth can be used to monitor teachers' performance. That helps the teachers to have a proper attitude toward teaching as a whole.

\subsubsection{Post-class Feedbacks and Assessment}

Universities' teaching quality management team and other related department should select proper measures to provide guidance to teachers to help them take post-class feedbacks and assessment seriously. That is the pre-requisite of building interactive communication between teachers and students. Only in this way can both teachers and students receive feedbacks from each other effectively.

\subsection{Research and Improvement Perspective}

The research on English teaching and the quality of English teaching are strongly correlated because English teaching research helps English teachers to optimize the structure of the curriculum, be more confident in teaching and gain better career development (Borg, 2006). In other words, high quality research plays an essential role in improving teaching quality. Therefore, universities should try their best to encourage English teachers to do academic research as much as possible given that daily teaching activities are not deteriorated.

The teaching quality management team and other related department need to evaluate English teachers' research based on the number, quality and the applicability of the related research. That helps the teachers to realize the importance of academic research. Hence, teaching methodology and structure can be continuously enhanced in the teaching process.

\subsection{Quantitative Teaching Result Perspective}

In regard of the Quantitative Teaching Result Perspective, universities should set improving students' internal test result, external English test result as well as Employment rate as the goal, and use the measures based on goals above to guide English teaching.

A well-designed and completely captured evaluation system should not only include short term measures but also include mid-term and long term performance evaluation measures (Simons, 1995). This is because short term based measures helps the management team to know the current weaknesses and problems in the organization. Mid-term based and long term based evaluation measures, on the other way, help employees to remember that they should not only focused on short term benefit by sacrificing the long term benefit of the organization as a whole (Powers, 2010). This kind of evaluation system should be introduced into building English teachers' evaluation system particularly when building the evaluation system from Quantitative Teaching Result Perspective.

\subsubsection{Short Term based Measurements - the Result of Internal Test}

The result of internal English test is a short term based measure, which can evaluate teachers' teaching performance within a short period (usually one semester). This measure can help to detect the problems that exist in the teaching process within a short period so that correction actions can be taken as soon as possible.

\subsubsection{Mid-term based Measurements - the Result of External Test}

The result of external test is a good mid-term based measure because it provides, to a large extent, a relatively object and fair test environment to universities to evaluate the effectiveness of teaching in a period of time. The external test can include the international English test, for example International English Language Testing System (IELTS). It can also include some national and international English competition. Universities can either compare their current result vertically against the time line or compare their result horizontally with other universities to evaluate the quality of English teaching with other universities. To add this measure into the teaching quality evaluation system not only motivate teachers to help student to develop the skills involved to take part in the external tests but also provides a relatively object benchmark to compare with other universities to find out the weaknesses and problems in English teaching area.

\subsubsection{Long Term based Measurements-Employment Rate of Graduates}

Today, the level of English a candidate can control is one of the most important factors when employers recruiting. Employment rate of graduates, as a long term based measure, helps the management team of evaluating teaching 
quality to determine whether teaching staffs have paid enough attention to develop students' English application skills. To include this long term based measurement helps teachers to remember that their duty is to develop students' English application skills instead of developing students' skills in doing exams and the English education is likely to be less exam-oriented generally.

\section{The Effectiveness of Each Measure within the Evaluation System}

After finding out the proper measures based on Balance Score Card, the quality and characteristics of each measure should be analyzed to find out the potential weaknesses that exist in each measure. In the enterprise performance management, the most ideal measures are those that are object, complete and responsive and analysis should follow the objective, complete and responsive turn (Simons, 2000).

For example, the above mentioned the students' result in internal and external tests are all objective measures since it can be judged on the score that each student achieved. On the other way, the quality level of the preparation of teaching materials is not an objective measure since the level of quality level is judged according to the management team instead of an objective score. For the completeness of each measure, since the result of internal English tests can only reflect teachers' teaching performance within that semester, it is an incomplete measure. However, for the result of external English test, because tests like IELTS test can, to a large extent, reflect the overall English skills of each candidate, hence the quality of teaching each student received, it is a rather complete measure. In regard of the responsiveness of a measure, as the teaching quality in a semester is much easier to be improved than the overall quality of teaching (the result of Internal tests more sensitive to teachers' devotion), the result of internal tests is a rather responsive measure compared with that of external tests.

What need to be aware of is that when a measure is incomplete but responsive, employees may get involved into activities that can improve their measure based performance but have little benefits for the organization as a whole (Simons, 2000). For example, for the result of internal tests, teachers may decrease the level of difficulty or even provide solutions to students to improve students' performance to help them to reach required level of the measure. When using this kind of measures, the teaching quality management team should be very careful and try to use other measures as complementary measures to ensure that such activities can be eliminated.

An objective, complete and responsive measure is very difficult to be found Therefore, teaching quality management team need to analyze each measure carefully to ensure that the drawbacks of a single measure can be sorted out.

\section{Conclusion}

The objective of the study is to investigate the application of balance score card in the quality control of university English teaching. The study is motivated by finding a system that is able to accurately and fully measure university English teaching quality by utilizing the ideas in enterprise management studies.

There are a number of findings in this paper. Firstly, from the ideas of balance score card used in enterprises, the evaluation of university English teaching quality can be divided into four levels, which are student level, teaching process level, self-improvement and research level, and teaching result level. Secondly, teaching goals should be set based on the four above levels. That allows the relevant measurements to be selected according to each specific goal at each level. Finally, each measure should be analyzed by following the objective, complete and responsive turn during the application process to ensure that the potential weaknesses cannot influence the objectivity of the evaluation system of English teaching. According to the findings of this study, it is recommended that university quality management team take into account the above four levels and the above three natures of each measure when setting goals and selecting specific measures for evaluating English teachers' teaching quality.

\section{References}

Borg, S. (2006). Conditions for teacher research. English Teaching Forum, 44(4), 22-27.

Cobbold, I., \& Lawrie, G. (2002). The development of the Balanced Scorecard as a strategic management tool, 2GC Active Management.

Crawford, F. (1991). Total Quality Management, Committee of Vice-Chancellors and Principals Occasional Paper, London, December, Cited in Hill, F. M. (1995) Managing service quality in higher education, the role of the student as primary consumer. Quality Assurance in Education, 3(3), 10-21. 
Davies, S. (2002). Marketing in higher education: matching promises and reality to expectations. Responding to Student Expectations, OECD report, pp. 103 -114.

Jensen, M. C., \& Meckling, W. H. (1976). Theory of the Firm: Managerial Behaviour, Agency Costs and Ownership Structure. Journal of Financial Economics, 3(4), 305-360.

Kaplan, R., \& Norton,D. (1992). The Balanced Scorecard - Measures That Drive Performance Harvard Business Review, 1992. January/February. pp. 71-79.

Powers, D. E. (2010). The case for a comprehensive, four-skill assessment of English language proficiency. $R \& D$ Connections, No. 14. Princeton, NJ: Educational Testing Service.

Simons, R. (2000). Performance Measurement and Control Systems for Implementing Strategy. New Jersey, United States of America: Princess-Hall, Inc.

Simons, R. (1995). Levers of Control: How Managers Use Innovative Control Systems to Drive Strategic Renewal. United States of America: Harvard Business School Press.

Telford, R., \& Masson, R. (2005). The congruence of quality values in higher Education. Quality Assurance in Education, 13(2), 107-119.

Theall, M. (2002). Student Ratings: Myths vs. Research. Focus on Faculty, 10(3), 2-3.

Tricker, T. (2005). Student Expectations - How do we measure up? In F. McMahon, \& T.Claes (Eds.), Probing the Boundaries of Higher Education (pp. 111-114). Oxford, U. K.: Inter-Disciplinary Press.

Wang, Y. (2006). English Teaching by the Theory of Blending Learning. China Educational Technology, 6(7), 67-69. 